\title{
A NAÇÃo COMO RELIGIÃO
}

\author{
Luís Machado de Abreu \\ Universidade de Aveiro, Portugal
}

\begin{abstract}
Resumo: As formas originárias de organização social mostram a estreita interdependência entre sistemas políticos e sistemas religiosos. A pregnância religiosa atribuída ao fenómeno da nacionalidade insere-se nesse cenário de proximidade genealógica do político e do teológico. Os mitos fundadores com que as nacionalidades se legitimam e sacralizam são apenas uma das várias maneiras de conferir dimensão religiosa à realidade nacional. Sendo uma criação dos tempos modernos, o espírito nacional acompanha e difunde-se ao mesmo tempo que se intensifica o processo de secularização da sociedade ocidental. Assume, de modo paradoxal, o estatuto de "Deus da Modernidade" como já foi designado.
\end{abstract}

Palavras-chave: Nação; religião civil; secularização; Rousseau; Tocqueville.

\section{Nação e simbólica religiosa}

As formas originárias de organização social mostram a estreita interdependência entre sistemas de administração e governo, e sistemas religiosos. A pregnância religiosa atribuída ao fenómeno da nacionalidade insere-se neste cenário de proximidade genealógica do político e do teológico. Os mitos fundadores com que as nacionalidades se legitimam e sacralizam são apenas uma das maneiras de conferir dimensão religiosa à realidade nacional. Mas existem outras, como as narrativas escatológicas nas quais a nação é chamada a desempenhar uma missão salvífica ou quando procede à consagração de heróis como, no caso português, D. Nun'Álvares Pereira ou à de antiheróis como o vencido de Alcácer-Quiibir e a mística sebastianista.

Enquanto realidades proteiformes, geralmente as nações imaginam-se enobrecidas por enraizamentos antiquíssimos, sendo embora, sob muitos aspectos, uma criação dos tempos modernos. Nessa medida, o espírito nacional acompanha e difunde-se ao mesmo tempo que se intensifica o processo pós-cristandade de secularização da sociedade ocidental. E a nação assume, de modo paradoxal, o estatuto de "Deus da Modernidade" (Josep Llobera). Mas em vez de se identificar como o deus da modernidade, não deverá a nação ser vista antes como uma, e uma apenas, entre as muitas divinizações operadas pelo dinamismo secularizador?! Não conheceram os Tempos Modernos vários outros substitutos da divindade, o sujeito individual, o progresso, a classe, o capital, a raça, a ciência?! 
Sabemos que a tomada de consciência das formações nacionais acompanha a progressiva afirmação da modernidade e atinge o auge no quadro das transformações civilizacionais dos séculos XIX e XX. Neste processo, foi possível assistir ao aparecimento de formas de organização administrativa e de construção identitária que, reforçando a singularidade das configurações nacionais, as determinava a adoptar procedimentos de competição com os outros povos. E o movimento pelo qual se reforçava a sociabilidade interna e a vontade de diferenciação com o universo exterior recorreu intensamente à valorização religiosa dos vínculos unificadores da colectividade. É, por essa via, que a nação chega a revestir-se de alguns atributos habituais das religiões e a desencadear práticas rituais e simbólicas que vão muito para além da imitação exterior e analógica das liturgias religiosas, assumindo-se de facto a nação como entidade sacralizada e envolta em sentimentos e demonstrações de culto religioso.

Não está nos propósitos desta exposição fazer história nem sociologia política das nacionalidades no Ocidente. As últimas décadas viram o interesse da investigação muito focado nesse estudo, de tal modo que dispomos hoje de importantes e esclarecedoras contribuições nesta área. O intento do conjunto de reflexões aqui proposto insere-se no quadro da história das ideias e pretende mostrar como se foram elaborando as articulações entre o fenómeno das nacionalidades e a sua configuração religiosa. Cruzamos assim experiências que remetem para o estatuto político da religião, tão caro ao discurso sociológico de Marcel Gauchet. A trajectória para o efeito traçada nesta cartografia intelectual vai pôr em relevo três pontos: a concepção de religião civil formulada por Jean-Jacques Rousseau no Contrato Social, a leitura "religiosa" da Revolução Francesa feita por Tocqueville, a construção social das formas religiosas e a sua aplicação aos factos nacionais.

\section{A religião civil}

Em carta dirigida a Voltaire, com data de 18 de Agosto de 1756, Jean-Jacques Rousseau dizia que "em cada Estado devia haver um código moral, uma espécie de profissão de fé civil” (Apud Chevallier, 1979:157). Pretendia por essa via garantir o reforço da solidez e respeito pelo espírito social consagrado nas leis que devem reger a vida em sociedade.

Aquando da redacção do Contrato Social, o capítulo sobre a religião civil não constava do plano inicial. Acabou por ser redigido bastante tardiamente e por figurar como último capítulo, antes da conclusão da obra. Nele, o autor esboça as linhas mestras do que julga ter sido o percurso histórico das relações entre o poder teológico e o poder político. Parte daquela situação em que entre a divindade e os seus representantes à 
frente do agrupamento das famílias existe uma unidade perfeita, situação instituída desde os tempos primordiais e ainda durante a época dos reinos pagãos. Vigorava então a teocracia com deuses a presidir aos destinos de cada cidade. E quando as disputas entre grupos rivais acabavam em guerras entre os povos, estas eram de natureza política e não religiosa. Os homens não combatiam para defender os deuses da Cidade. Acreditavam que os deuses estavam ao seu lado para servir a mesma causa. Faziam a guerra para defender a pátria e esperavam igual protecção dos deuses que invocavam como salvadores do seu povo. Esse estado de unidade foi quebrado com o aparecimento do cristianismo que introduziu a separação entre o sistema religioso e o sistema político, ao exigir que se dê a César o que a César pertence e instituindo o reino de Deus, reino que não é deste mundo.

Este quadro histórico fornece o cenário sobre o qual vai ser concebida a teoria de Rousseau acerca da religião civil. O autor elabora-a recorrendo à desconstrução da função política do cristianismo. Procede em duas etapas.

Na primeira, trata precisamente da separação que a doutrina cristã estabelece entre duas pátrias, duas legislações, dois chefes, o reino dos céus e a cidade dos homens. Mas a separação não garante autonomia de cada um dos lados, e os conflitos que nascem de paixões e interesses opostos acabam por perturbar a sociabilidade e semear a discórdia, colocando os homens uns contra os outros e o mesmo homem dividido dentro de si mesmo. As lutas medievais entre o Papado e o Império e, nos séculos XVI e XVII, as guerras de religião documentam com tragédias sociais e culturais efeitos indesejáveis da separação. Diremos então que Rousseau continuava a viver a nostalgia das sociedades pagãs onde os deuses existem para a Cidade e não a Cidade para os deuses. Mas sabia que o aparecimento do cristianismo tornou definitivamente obsoleto o regime político do paganismo antigo.

A segunda etapa corresponde ao que Rousseau chama "a religião do homem", "a pura e simples religião do Evangelho, o verdadeiro teísmo” (Rousseau,1967:419). Numa primeira aproximação, esta forma de religião toda interior e aplicada à prática da perfeição moral concentra a simpatia dos espíritos bem formados. Todavia não devemos ignorar que há nela uma enorme e fatal lacuna, uma vez que "por não ter nenhuma relação particular com o corpo político, deixa às leis apenas a força que tiram de si mesmas sem lhes acrescentar mais nada" (Rousseau, 1976:422). E não só não reforça o poder normativo da lei, como de vários modos atenta contra os vínculos de sociabilidade. O autor do Contrato Social reedita então as diatribes do filosofismo das Luzes contra o cristianismo em geral e a Igreja Católica em particular. Acentua o carácter decisivo do espiritualismo cristão, vendo nele a disposição para tratar com 
indiferença e falta de efectivo compromisso as coisas da existência temporal e social. E considera que a pátria do cristão não é deste mundo. Se no dia-a-dia das sociedades, os cristãos também desempenham as tarefas habituais, fazem-no não por amor à pátria onde nasceram, mas para continuarem a poder servir, acima de tudo, o reino de Deus. De olhos postos na pátria celeste, tudo quanto acontece, para bem ou para mal, é atribuído à Providência, favorecendo assim uma atitude de resignada passividade.

É claro que quem quiser conhecer com rigor as implicações de ordem política contidas na fé cristã andará muito mal se ficar pelas pinceladas sumárias de Rousseau. Na verdade, a caracterização doutrinal que aí encontramos tem de ser entendida como claramente omissa em relação à dimensão social que, desde sempre, integra a fé e que o catolicismo social, a partir do século XIX, foi assumindo com progressiva visibilidade. Mas temos de lhe dar razão quando afirma que o Evangelho não funda nenhuma religião nacional, apesar de em vários momentos da história política ter estado associado a tentativas teocráticas. Mas as teocracias que teriam sido o primeiro dos regimes quando os homens não tinham outros reis a não ser os próprios deuses, multiplicaram as sociedades políticas e os respectivos deuses favorecendo ódios, divisões, guerras entre os povos. Com as divisões nacionais nasciam as intolerâncias teológicas e as civis.

A enunciação do princípio da separação da cidade de Deus e da cidade dos homens afigura-se, segundo esta análise, ambivalente. Se, por um lado, pode produzir desapego e alheamento relativamente à vida da Cidade, por outro, cria condições para a autonomia das realidades terrestres.

A religião pura do Evangelho trouxe, no plano dos princípios, a afirmação da separação entre Deus e César, entre o teológico e o político. Falta, porém, levá-la à prática, fugindo de todas as manobras que têm visado a sua perversão, quer sob a forma de alheamento ou indiferença perante a coisa pública quer com tentativas de usurpação e domínio do poder de governar por parte dos eclesiásticos. Para contrariar estas tendências, a soberania da lei precisa de ser respeitada e fortalecida. Só então ficará garantido o bom funcionamento do corpo político, a segurança do Estado e a liberdade dos cidadãos.

Há aqui lugar para atitudes que são herdeiras de comportamentos alimentados pela doutrinação das religiões tradicionais. Mas delas se distinguem quanto ao objecto e quanto á função. O objecto dessas atitudes de fé e de veneração cultual é a realidade social do Estado enquanto pátria e organização nacional. E têm como função principal promover a moralidade no relacionamento dos cidadãos entre si e com o organismo da 
sociedade. Importa, por isso, ao Estado que os cidadãos tenham uma religião que os disponha a servir a "santidade do contrato social e das leis" e que os faça amar os seus deveres. Tal é a natureza e o alcance da chamada religião civil apresentada por Rousseau nestes termos:

\footnotetext{
Há portanto uma profissão de fé puramente civil da qual pertence ao soberano fixar os artigos, não precisamente como dogmas de religião, mas como sentimentos de sociabilidade, sem os quais é impossível ser-se súbdito fiel ou bom cidadão. Sem poder obrigar ninguém a acreditar neles, pode banir do Estado quemquer que neles não acredite; pode bani-lo não como ímpio, mas como insociável, como incapaz de amar sinceramente as leis, a justiça, e de imolar, em caso de necessidade, a vida ao dever. (Rousseau,1967:427)
}

A desconstrução da função política do cristianismo conduziu num primeiro tempo à institucionalização do contrato como origem e fundamento da sociedade política. $\mathrm{O}$ poder soberano já não vem de Deus mas do pacto "pelo qual cada um, unindo-se a todos, não obedece, contudo, senão a si mesmo e permanece tão livre como antes" (Rousseau, 1967:90). Em segundo lugar, ficamos a dever-lhe a proclamação do princípio decisivo da separação entre o espiritual e o temporal, entre o que se pode dever a Deus e o que a César é devido. E com esta separação pretende-se ainda que fiquem afastadas de vez quaisquer pretensões de recomposição, ainda que larvar, do regime teocrático.

A religião civil, em vez de subordinar o corpo político a interesses espirituais de índole transcendente, existe para cimentar a coesão contratual. Prossegue nesse objectivo de dois modos: sacralizando o pacto social, as leis e a associação dos cidadãos em Estado nacional, e fazendo a pedagogia dos direitos e do cumprimento dos deveres para com a colectividade.

Seja-me permitido recorrer aqui, por comodidade de linguagem, ao vocabulário hegeliano e à sua noção de Aufhebung. O efeito da Aufhebung consiste numa superação de que fazem parte, ao mesmo tempo, a acção de eliminar ou suprimir e o facto de conservar alguma coisa daquilo que se ultrapassa. A desconstrução de Rousseau visou eliminar a teologia política do cristianismo, mas ao secularizar a instituição do Estado nacional não se mostrou tão confiante na boa vontade dos cidadãos como se poderia esperar, nem tão optimista quanto à tranquila execução do contrato. E porque assim é, acha necessária uma "profissão de fé civil", uma religião civil de que espera garantias complementares ao cumprimento dos deveres dos cidadãos para com o Estado nacional. No fim de contas, a sociabilidade não está inscrita na natureza do homem como ser individual. Para que a sociabilidade adquira robustez e garantia de adesão por 
parte do indivíduo-cidadão, entendeu-se que era necessário recorrer à figura da religião civil.

Acontece que esta religião não é estática. Acompanha as vicissitudes históricas da sociedade e passa por metamorfoses que tanto reflectem épocas de triunfo e grande exaltação patriótica como fases de desilusão, desconforto e abandono. Ao aclimatar-se a diferentes povos e contextos, o modelo proposto por Rousseau modifica-se, renovandose, sofrendo actualizações, e nalguns casos atingindo formulações tão excessivas e paroxísticas que raiam as fronteiras da patologia social.

\section{Virtudes republicanas}

As ideias de Ser supremo, de imortalidade da alma e a importância social do sentimento religioso enquanto alicerces sobre os quais se ergue o edifício das virtudes republicanas ocupam o núcleo central da concepção de política nacional defendida por Robespierre. Graças a essas ideias, o ser humano deve adquirir a estabilidade capaz de superar a agitação das paixões que ameaça a prática da virtude. São elas que asseguram a constância das acções conformes ao bem do povo e ao interesse da República. Vencem as insuficiências da autoridade humana e consolidam os vínculos de sociabilidade que animam as instituições.

Existe nesta proclamação e defesa de ideias religiosas uma declarada inspiração deísta. Não só ignora a religião cristã e católica tradicional, como se demarca furiosamente do clericalismo. Mas recusa também com veemência o ateísmo, pois, no dizer de Robespierre, "é o sentimento religioso que imprime nas almas a ideia de uma sanção dada aos preceitos da moral por uma potência superior ao homem. Por isso, que se saiba nenhum legislador tratou jamais de nacionalizar o ateísmo.” (Robespierre, 1965:264)

Se, em rigor, não se trata de atribuir à República estatuto de religião, verifica-se pelo menos uma interiorização moral dos comportamentos em que alguns princípios teológicos aparecem investidos de valor moral, servindo de alicerce às virtudes republicanas. Estas não se esgotam no assegurar de formas sociáveis de comportamento feitas de respeito, fraternidade, dedicação à causa pública, amor da natureza. Alimentam e concretizam o sentimento religioso republicano de que fazem parte muitas outras manifestações. Assim acontece com as festas nacionais. (Robespierre, 1965: 276-286 passim) As festas são, em primeiro lugar, momentos de celebração da sociabilidade em que se olha para o que de mais excelente existe na humanidade, se apela para o respeito dos outros e do bem comum, ao mesmo tempo que se celebra o culto dos mais nobres acontecimentos e figuras da história da 
liberdade e da fraternidade, tudo sob os auspícios do Ser supremo. Exercem também uma função pedagógica insubstituível. Lembrar à nação os bons exemplos de dedicação à causa comum e de serviço público é educar no cidadão a vontade de ser melhor, de respeitar as leis e servir a pátria com amor.

\section{Leitura "religiosa" da Revolução}

A articulação da Revolução Francesa com a experiência religiosa tal como foi estabelecida por Tocqueville constitui um elo interessante do encadeamento histórico que viu a afirmação de religiões civis e de religiões políticas. Vejamos as três fases em que essa articulação se foi construindo.

Em primeiro lugar não se pode esconder que a revolução teve carácter irreligioso, com momentos de rejeição violenta da presença da Igreja na vida social e política da nação francesa. É uma relação de sinal claramente negativo, mas que está longe de ser tão radical como se pretendeu. E prova-se que assim sucedeu por duas razões principais. A irreligião cultivada pelo pensamento filosófico do século XVIII, como se viu em Rousseau, visava o cristianismo como instituição política poderosa e não tanto como doutrina religiosa, ou pelo menos, quando esta é atacada, as críticas vêm sobretudo de intelectuais e muito pouco da população em geral. Além disso, não é verdade que, por natureza, as sociedades democráticas são ou têm de ser hostis ao cristianismo. Pois não foram essas sociedades buscar ao cristianismo, e mesmo ao catolicismo, os princípios essenciais que dão forma ao espírito de fraternidade, igualdade e liberdade em que se baseia a organização democrática da sociedade ?!

Mas mais significativo que o lado revolucionário anti-religioso é o facto de a Revolução Francesa, enquanto processo político, proceder à maneira das revoluções religiosas. São várias as manifestações que dão conta dessa analogia de processos. Ao contrário das revoluções civis e políticas centradas num território e na defesa de interesses étnicos e sociais restritos, a Revolução de 1789 pretendeu criar uma pátria universal, acima das nacionalidades, onde os homens de todas as nações pudessem ser cidadãos. Esta vocação universal só tem paralelo em revoluções religiosas, como a fundação e difusão do cristianismo. Na sua origem encontram-se ideias novas e um espírito proselitista muito forte. O novo evangelho revolucionário não se destina apenas aos franceses. Propõe-se conquistar os homens independentemente da nacionalidade a que pertencem.

Depois da analogia quanto aos efeitos, procuremos ver se não existe igualmente analogia ao nível das causas que podem aproximar a Revolução Francesa da grande revolução moral operada pelo cristianismo. Quando investigada em profundidade, a 
razão que torna singular a revolução de 1789 , tal como a explicação para a transformação religiosa produzida pelo cristianismo encontra-se numa concepção de homem visto como ser concreto e universal. Concreto, isto é, como entidade dotada de consistência real, por oposição à visão abstracta e genérica da ideia de homem. Universal, porque o ser do homem não está cativo de particularismos de raça, geografia, língua e costumes.

A novidade do cristianismo verá em cada homem a criatura chamada à salvação em Jesus Cristo, seja ele judeu, grego ou romano. Já para a Revolução Francesa, o homem, francês, inglês, alemão ou de outra nacionalidade é sempre cidadão portador de direitos e deveres para com os outros seres humanos. A obra política da revolução confundia-se, pela primeira vez na história, depois do cristianismo, com a missão de regenerar a humanidade inteira. Daí as muitas paixões que desencadeou e os proselitismos e acções de propaganda que inspirou. Em síntese do próprio Tocqueville, a revolução tomou assim

\footnotetext{
o ar de revolução religiosa que tanto sobressaltou os contemporâneos. Melhor ainda, tornouse uma espécie de nova religião, religião imperfeita, é certo, sem Deus, sem culto e sem outra vida. Mas que, no entanto, como o islamismo, inundou toda a terra com os seus soldados, os seus apóstolos e mártires.” (Tocqueville, 1986: 960)
}

\section{Construção social das formas religiosas}

Entre as tendências culturais contemporâneas conta-se o deslindar dos estreitos laços que tradicionalmente faziam da religião uma força de coesão social alimentada por hábitos de participação comunitária. Foi à luz deste horizonte colectivo que, em começos do século XX, Durkheim construiu a teoria da origem social da religião. Hoje, porém, os destroços dessa religiosidade sociológica vão sobrevivendo, sobretudo, em comunidades de base, pequenos grupos e formas individualizadas de privatização da experiência religiosa.

Encontramos em Durkheim uma teoria da socialização do fenómeno religioso. A força e poder matricial reconhecidos ao comportamento religioso na medida da sua capacidade afectiva, simbólica e funcional tem a sua fonte na sociedade. Nesse poder matricial lançam raízes a moral, o pensamento filosófico, a própria ciência. Concluir-se-á, por isso, que "se a religião gerou tudo o que há de essencial na sociedade, é porque a ideia de sociedade é a alma da religião.” (Durkheim, 2007:132) Em natural conexão com esta explicação do "divino social" aparecem coerentemente legitimadas as formas religiosas em que a sociedade, além de ser causa dessas formas, se perfila também, em certa 
medida, como objecto de veneração e culto. Estão neste caso práticas laicas de cidadania que se deixam potenciar por estímulos de religiosidade nacionalista alimentados por representações simbólicas do colectivo e práticas rituais. Hino, bandeira, panteão, feriados e festas civis são algumas condensações cultuais da religião da pátria. A nação, comunidade imaginada, pólo de identificação colectiva, narrativa sagrada de um povo que acredita no seu destino. Assim entendida, a nação apresentase como forma particular de sociolatria.

Transfigurada em objecto de tratamento religioso, hispotasiada como entidade portadora de sentido absoluto, a nação já não cabe na ideia daquele território que nos viu nascer e que partilhamos afectivamente como memória sagrada dos antepassados. Também não cabe no conceito de Estado-nação constituído pela comunidade de cidadãos. Extravasa desses moldes afectivos e racionais, e eleva-se muito acima de uma existência que continuaria relativizada pelo facto de não passar de uma nação que faz número com muitas outras. Exaltada e oferecida como valor absoluto, já não estamos propriamente em presença de uma nação, mas do seu exacerbamento nacionalista. E é como nacionalismo que as marcas de religiosidade acabam por configurar mais vincadamente a relação com a nacionalidade.

\section{Religião e nacionalidade - uma relação paradoxal}

De qualquer modo, as dinâmicas sociais e simbólicas que, durante os séculos XIX e XX, acompanharam as peripécias políticas do princípio das nacionalidades evidenciaram $o$ largo espectro de ressonâncias afectivas e morais que fazem da nação um dado social muito mais extenso do que o de Estado com que às vezes é confundido. Para este aspecto, chamou Raoul Girardet a atenção, ao lembrar que "parece duvidoso que na sua realidade concreta, quotidianamente vivida, o destino de uma nação possa ser considerado como essencialmente redutível à afirmação do poder estatal.” (Girardet, 1996:75)

Abundam as expressões dessa exuberância sentimental, cultual, memorialística, glorificadora, transmitidas sob as mais diversas modalidades de comunicação mediática. A celebração da religião nacional passa através da literatura, das artes plásticas, música, festas locais e nacionais, actos cívicos, consagração de figuras e acontecimentos relevantes, desfiles militares, grandes feitos desportivos, entre outros.

Um dos momentos mais fascinantes de identificação religiosa da nacionalidade portuguesa aparece em pleno século XV, na Crónica de D. João I de Fernão Lopes, onde se fala do evangelho português e da sétima idade do mundo. O evangelho português assenta em duas profissões de fé, a que acredita no Mestre de Aviz como Defensor do 
reino de Portugal e garantia da sua existência independente contra as pretensões de Castela, e a que, em pleno Cisma da Cristandade Ocidental, professa obediência ao papa Urbano VI, o papa romano. As duas profissões de fé servem dupla unidade e continuidade, a do reino de Portugal e a da Cristandade sob o governo de Roma. Escreve Fernão Lopes:

\begin{abstract}
Assim o Mestre, depois que se dispôs a morrer [...] por salvação da terra que seus avós ganharam, enviou Nun'Álvares e seus companheiros pregar pelo reino o evangelho português, o qual era que todos cressem e tivessem firme o papa urbano ser verdadeiro pastor da Igreja, fora de cuja obediência nenhum salvar-se podia; e com isto ter aquela crença que seus padres sempre tiveram, convém a saber: gastar os bens e quanto haviam por defender o reino de seus inimigos, e como por manter esta fé espargiam seu sangue atá morte. A qual pregação Nun'Álvares e os seus, por palavra e obra fizeram tão cumpridamente que alguns deles, como depois vereis, foram mortos po-la defender..." (Fernão Lopes,1977:391).
\end{abstract}

Estamos em plena vigência do teológico-político medieval em que o vocabulário cristão é muito mais do que recurso meramente convencional. Instaura no espaço sacral da Cristandade as contingências da sucessão dinástica do rei D. Fernando e o destino nacional de um povo. $\mathrm{O}$ mesmo se deve dizer do cenário providencialista que envolve o lugar atribuído a esse povo na história. Os acontecimentos a que diz respeito o evangelho português são também os que inauguram um "mundo novo", uma nova idade do mundo.

A simples evocação do campo religioso põe de sobreaviso a capacidade discursiva racional e deixa pairar a suspeita de que são incompatíveis as esferas da religião e da racionalidade. A realidade, porém, parece bastante mais densamente complexa, e disso mesmo encontramos exemplos no modo como se ocupam dessas questões os autores acima referidos. Tentaram sempre compreender e explicar, na medida do que julgavam possível, o sentimento religioso como factor político de experiências revolucionárias, reformadoras e organizativas da vida da nação. O espanto perante essa espécie de numinoso que envolve a origem das nações sentiu-o também Alexandre Herculano. Ao procurar as causas que deveriam explicar a origem e permanência da nação portuguesa, quando tantas outras repúblicas ricas, poderosas e mais antigas se dissolveram e anularam, o autor da História de Portugal não encontra melhor que remeter a questão para o domínio do "mistério" ou do "fenómeno aparentemente inexplicável" (Herculano,1907: 31).

À semelhança do que acontece nas religiões, sobretudo quando se afirmam militantemente proselitistas, a religiosidade nacionalista alimenta-se de apelos à conversão e de distanciamento em relação a tudo o que, sendo estrangeiro, deve ser 
evitado como ímpio, perverso e ameaçador. Os elementos distintivos da nacionalidade, se proporcionam as marcas identitárias de um povo, também podem transviá-lo pelas sendas do egoísmo chauvinista. E não falta mesmo, em casos extremos, a imolação no altar da pátria de todas as experiências históricas de contaminação racial. Com alguma frequência, a salvaguarda da pureza da raça acompanha a exaltação nacionalista mais desenfreada da sacralidade colectiva. Não é outro o pressuposto invocado por António Sardinha em O Valor da Raça Introdução a uma Campanha Nacional quando sentencia que é “do pouco escrúpulo em nos aparentarmos com ligações asiáticas e africanas [que] deriva o nosso desfalecimento em linha recta. [...] Não se justifica nem se compreende de outra maneira a dissolução entre nós de toda a ideia colectiva." (Sardinha,1915:115)

Aqui chegados, a religião da nação converteu-se em aberrante fundamentalismo.

O tratamento da nação como algo que inspira sentimentos de reverência e piedosa devoção pode surgir em contextos ideológicos algo surpreendentes. A título de exemplo veja-se a Cartilha de Doutrina Filosofica por um Lusiada publicada em Lisboa, no ano de 1925. É um opúsculo de trinta e seis páginas redigido à maneira de catecismo. Ideologicamente identifica-se como monista, em filosofia, e defensor do Estado democrático, em política.

O teor religioso desta cartilha nacional aparece desde as primeiras páginas, onde encontramos três orações à pátria, que decalcam outras tantas orações do devocionário cristão, e seis "artigos de Fé Pátria". A oração "Pátria-Nossa”, entre o devoto e o paródico, reza assim:

Pátria-Nossa, divina Pátria de Camões e Nun'Álvares, santificado seja o vosso nome. Venha a nós o vosso valor e a vossa glória. Seja feita a vossa vontade em nossas almas. Dai-nos em cada dia o pão imortal da esperança, e perdoai, Senhora, os nossos erros. Para nos libertarmos de toda a fraqueza e de todo o crime, encheremos os corações do vosso amor. Amem. ( Cartilha, 1925: 6)

Nesta atitude orante, a realidade sociológica da consciência nacional de um povo fica inteiramente objectivada como entidade superior em relação à qual os deveres do cidadão se transcendem em arrebatamentos místicos e práticas cultuais. A instituição nacional abandona o território comum do mundo empírico e eleva-se à esfera do sagrado e do religioso.

É uma situação profundamente paradoxal. O espírito da modernidade define-se como aquele projecto em que o homem, servindo-se da razão, pretende ser o construtor do seu próprio destino, como indivíduo e como cidadão. É claramente um projecto de 
autonomia, servido objectivamente pelo processo de secularização que dessacraliza as realidades temporais e caminha para a instauração da laicidade na organização da Cidade. Ora, a inscrição da consciência nacional no registo do religioso, qualquer que seja a natureza deste, remete sempre para um certo grau de heteronomia. E proceder assim, "seria, de maneira subreptícia, tomar o caminho de um radical pôr em causa a secularização. Seria preparar o lugar para nova instância religiosa que pretenderia, mais uma vez, impor a determinação do sentido da sociedade.” (Coq,1995:144-145) Este paradoxo é uma encruzilhada onde a reflexão tem muito que pensar, e que pensar em várias direcções.

A perspectiva que enquadra a nação na esfera religiosa acaba sempre por remeter para outra e primordial questão. Ler e interpretar a nação como entidade sacral, feita de valores, símbolos e rituais identificados como religião pressupõe que se estabeleça o estatuto do religioso na modernidade, quer sob o signo das "deslocações do crer" (Michel de Certeau), quer sob a forma de "saída da religião" (Marcel Gauchet), quer ainda sob "a figura metafísica do religioso" (Luc Ferry). Eis três caminhos por onde pode e deve discorrer o pensamento sobre a nação como religião.

\section{Referências bibliográficas}

Cartilha de Doutrina Filosofica por um Lusiada (1925). Lisboa, ,[s. e.]

Certeau, Michel de (1980), L'invention du quotidien 1/ Arts de faire. Paris, Union Générale d'Editions

Chevallier, Jean-Jacques (1979), Histoire de la pensée politique. T.2 - L'État-nation monarchique: $\quad$ vers le déclin. Paris, Payot

Coq, Guy (1995), Laïcité et République Le lien nécessaire. Paris, Ed. du Félin

Días-Salazar, Rafael, Salvador Giner, Fernando Velasco (eds.) (1994), Formas modernas de religión. Madrid, Alianza Editorial

Durkheim, Émile (2007), Les Formes élémentaires de la vie religieuse. Présentation par Michel Maffesoli. Paris, CNRS Editions

Ferry, Luc, Marcel Gauchet (2004), Le Religieux après la religion. Paris, Grasset

Gauchet, Marcel (1985), Le Désenchantement du Monde Une Histoire Politique de la Religion. Paris, Gallimard

Gauchet, Marcel (2002), La démocratie contre elle-même. Paris, Gallimard 
Girardet, Raoul, (1996) Nationalismes et Nation. Bruxelles, Éditions Complexe

Herculano, Alexandre (1907), "Cogitações soltas de um homem obscuro", in: A. Herculano, Opúsculos. T. VI. $3^{\mathrm{a}}$ edição. Lisboa, Antiga Casa Bertrand - José Bastos \& C. ${ }^{\mathrm{a}}$

Llobera, Josep R., (2000) O Deus da Modernidade O Desenvolvimento do Nacionalismo na Europa Ocidental. Tradução de Vítor Ferreira. Oeiras, Celta Editora

Lopes, Fernão (1977 ), História de uma Revolução Primeira parte da Crónica de ElRei D. João I de Boa Memória. Actualização do texto, introdução e notas de José H. Saraiva. Mem Martins, Publicações Europa-América

Robespierre (1965), "Sur les rapports des idées religieuses et morales avec les principes républicains et sur les fêtes nationales" (1794), in: Robespierre, Discours et Rapports à la Convention. Paris, Union Générale d'Editions

Rousseau, J.-J. (1967), Du Contrat Social. Introduction, notes, commentaire par Maurice Halbwachs. Paris, Aubier-Montaigne

Sardinha, António, (1915), O Valor da Raça Introdução a uma Campanha Nacional. Lisboa, Miranda \& Sousa Editores

Tocqueville, (1986), “L'Ancien Régime et la Révolution” (1856), in: Tocqueville, De la Démocratie en Amérique, Souvenirs, L'Ancien Régime et la Révolution. Paris, $\quad$ Ed. Robert Laffont

Luís Machado de Abreu é Professor Catedrático aposentado da Universidade de Aveiro. Licenciado (1977, Faculdade de Letras da Universidade de Lisboa) e doutorado em Filosofia (1982, Universidade de Paris X - Nanterre e École Pratique des Hautes Études - V ème Section, Paris; 1991, Universidade de Aveiro). Foi coordenador científico do Centro de Línguas e Culturas da Universidade de Aveiro durante os anos de 2000/2002. Como investigador do mesmo Centro, desempenhou funções de coordenador do grupo de investigação em Cultura Portuguesa. Coordenou igualmente, até 2007, uma linha de investigação que estudava o Anticlericalismo em Portugal. Tem uma vasta obra publicada.

luismabreu@ua.pt 